\title{
Acessibilidade em edificações: acesso principal ao Hospital Universitário Walter Cantídio
}

\section{(Accessibility in buildings: main entrance to the University Hospital Walter Cantídio)}

\author{
JESSICA BRUNA TEIXEIRA MAIA \\ Estudante, Universidade Federal do Ceará, jessicamaia@arquitetura.ufc.br \\ LORENA LOPES BEZERRA DE SOUSA LIMA \\ Estudante, Universidade Federal do Ceará, lorenalopes@arquitetura.ufc.br
}

\begin{abstract}
RESUMO
O presente artigo trata-se da análise da recepção do Hospital Universitário Walter Cantídio (HUWC), localizado no bairro Rodolfo Teófilo, em Fortaleza-Ce, objetivando observar questões como a acessibilidade do espaço e de seus dos acessos a toda e qualquer pessoa. Este trabalho advém da disciplina optativa de Desenho universal, ministrada pela professora Zilsa Maria Pinto Santiago, na Universidade Federal do Ceará. A sua execução foi feita através de métodos de análise para a verificação à adequação do ambiente a NBR 9050, dos quais foram separadas em etapas de vivência do local, coleta de dados, análise de dados, compatibilização de normas e viabilidade de um possível projeto resultando na percepção de necessidade de mudanças e criações de alguns elementos para a adequação da recepção e da chegada à mesma à norma, a fim de torná-la acessível universalmente.
\end{abstract}

PALAVRAS-CHAVE: Acessibilidade, Hospital, Arquitetura.

\begin{abstract}
This article is a study of accessibility in public buildings, taking as an example the analysis of the reception of the Walter Cantídio University Hospital (HUWC), located in the Rodolfo Teófilo neighborhood, in Fortaleza-Ce, aiming to observe issues such as the accessibility of space and their access to anyone and everyone. This work comes from the optional discipline of Universal Design, taught by Zilsa Maria Pinto Santiago, at the Federal University of Ceará. Digital tools were used to better visualize the location, such as a previous survey of the hospital. The research was carried out using analysis methods to verify the adequacy of the environment to NBR 9050, which were separated into stages of experiencing the site, data collection, data analysis, compatibility of standards and feasibility of a possible project resulting in the perception of the need for changes and the creation of some elements for the adequacy of reception and arrival to the standard, in order to make it universally accessible.
\end{abstract}

KEYWORDS: Accessibility, Hospital, Architecture. 


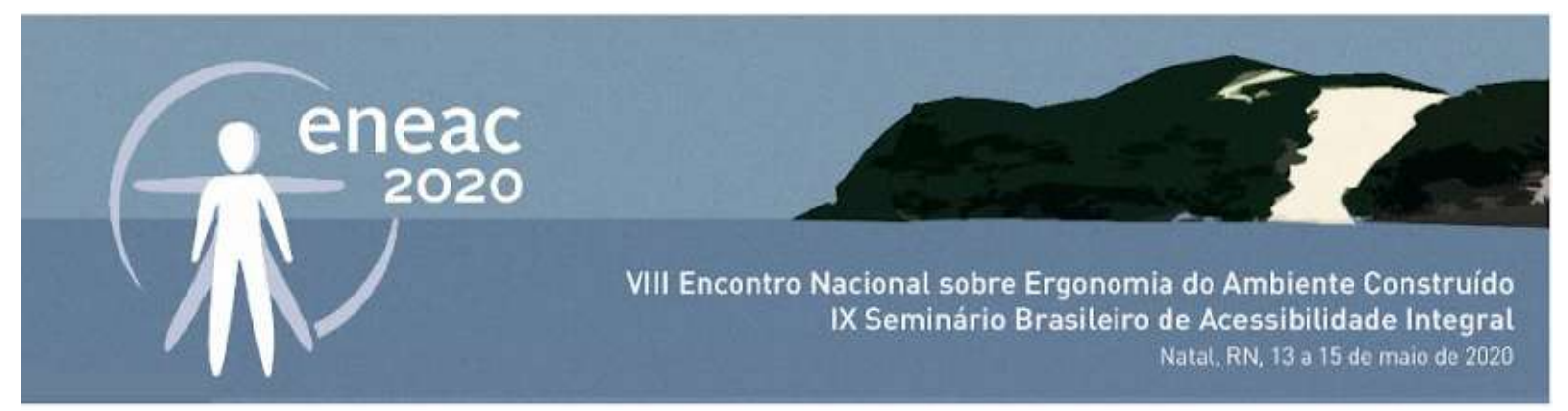

\section{INTRODUÇÃO}

Acessibilidade é a garantia de que toda e qualquer pessoa possa transitar livremente sem maiores dificuldades por onde desejar ir. Como já dizia Gehl:

"A mobilidade é um componente essencial à saúde da cidade [...] $O$ ritmo do encontro é o ritmo da caminhada. Precisamos desenhar as nossas cidades para que o espaço do pedestre seja determinante..."

- GEHL, Cidade para pessoas (2013)

Sendo assim, é importante ressaltar o contexto de Fortaleza, onde se percebe que, o direito de ir e vir ainda é defasado para pessoas com deficiências de locomoção. Para exemplificar a afirmação, será analisada a chegada à recepção do Hospital Universitário Walter Cantídio, localizado na Rua Pastor Samuel Munguba, bairro Rodolfo Teófilo, por dados levantados entre setembro e novembro de 2019.

O hospital estudado conta com um programa extenso, tendo em vista que engloba também a Faculdade de Medicina da Universidade Federal do Ceará, sendo assim, diariamente frequentado por médicos, enfermeiros, pacientes, estudantes, enfim, uma extensa variedade de pessoas. É um equipamento importante para a área em que se insere, para toda a cidade de Fortaleza e também atende a casos específicos a todo o estado do Ceará, o que justifica a presente análise.

Num projeto arquitetônico verifica-se tanto a necessidade de pensar cautelosamente a funcionalidade do interior do edifício, como a relação espaço externo-ambiente urbano. É importante que o projeto seja concebido de forma que as áreas de de acesso ao edifício possam atender a todas as pessoas, inclusive as possíveis limitações dos seres humanos. É fundamental que ao pensar em acessos para equipamentos públicos, leve-se em consideração a diversidade de pessoas a se utilizar do equipamento, ou seja, idosos, gestantes, pessoas com deficiência motora e sensorial (deficiência física, visual e auditiva). Em se tratando de hospital, que é o caso estudado, pessoas com dificuldade de locomoção provocada por alguma eventual doença, e por isso existem normas criadas para que a edificação se torne acessível também para essas pessoas.

A norma em que a análise do presente artigo se baseia, fundamentalmente, é a NBR 9050 Acessibilidade a edificações, mobiliário, espaços e equipamentos urbanos, de 2004, que foi criada a fim de instruir arquitetos, projetistas, engenheiros e outras profissões ligadas à área de construção civil no tocante a universalidade que o desenho arquitetônico e urbanístico precisa alcançar.

A NBR 9050 traz padrões mínimos a serem seguidos para tornar a edificação acessível. Esses padrões citados pela norma existem para universalizar a presença e o uso do equipamento, tendo assim, que serem seguidos metodicamente.

\section{METODOLOGIA}

O estudo acerca das condições de acessibilidade do acesso principal ao HUWC inicia-se por estudos bibliográficos, levando em consideração conceitos fundamentais, como de "Acessibilidade" e "Arquitetura universal", para que se entenda a arquitetura acessível não como um tipo específico de projeto, mas que a ideia de que arquitetura e universalidade se alinhem como premissas fundamentais e indispensáveis para a elaboração de um espaço. 
Para a análise buscou-se também o estudo da legislação pertinente, de artigos nacionais, normas, manuais, tendo como processo a elaboração de cinco etapas de pesquisa de campo: 1 . Análise subjetiva presencial por vivência no local, onde foi vivenciado o ambiente percorrendo o trajeto como um usuário cotidiano do local, tentando assim se aproximar o máximo da realidade existente; 2. Levantamento, a partir dessa primeira impressão foram colhidos todos as informações consideradas relevantes para o estudo; 3 . Identificação de incompatibilidades com normas e manuais que regularizam os pontos levantados, nessa etapa os dados coletados anteriormente foram rigorosamente comparados às normas vigentes; 4 . Viabilidade do projeto, que consistiu em um estudo da necessidade e possibilidade de uma intervenção; 5 . Relatório com possibilidades de compatibilização; 6. Projeto de compatibilização, nesse item foram listados os problemas e respectivas sugestões de soluções que não destoassem da linguagem existente, além de o orçamento ter sido levado em consideração.

\section{ANÁLISE}

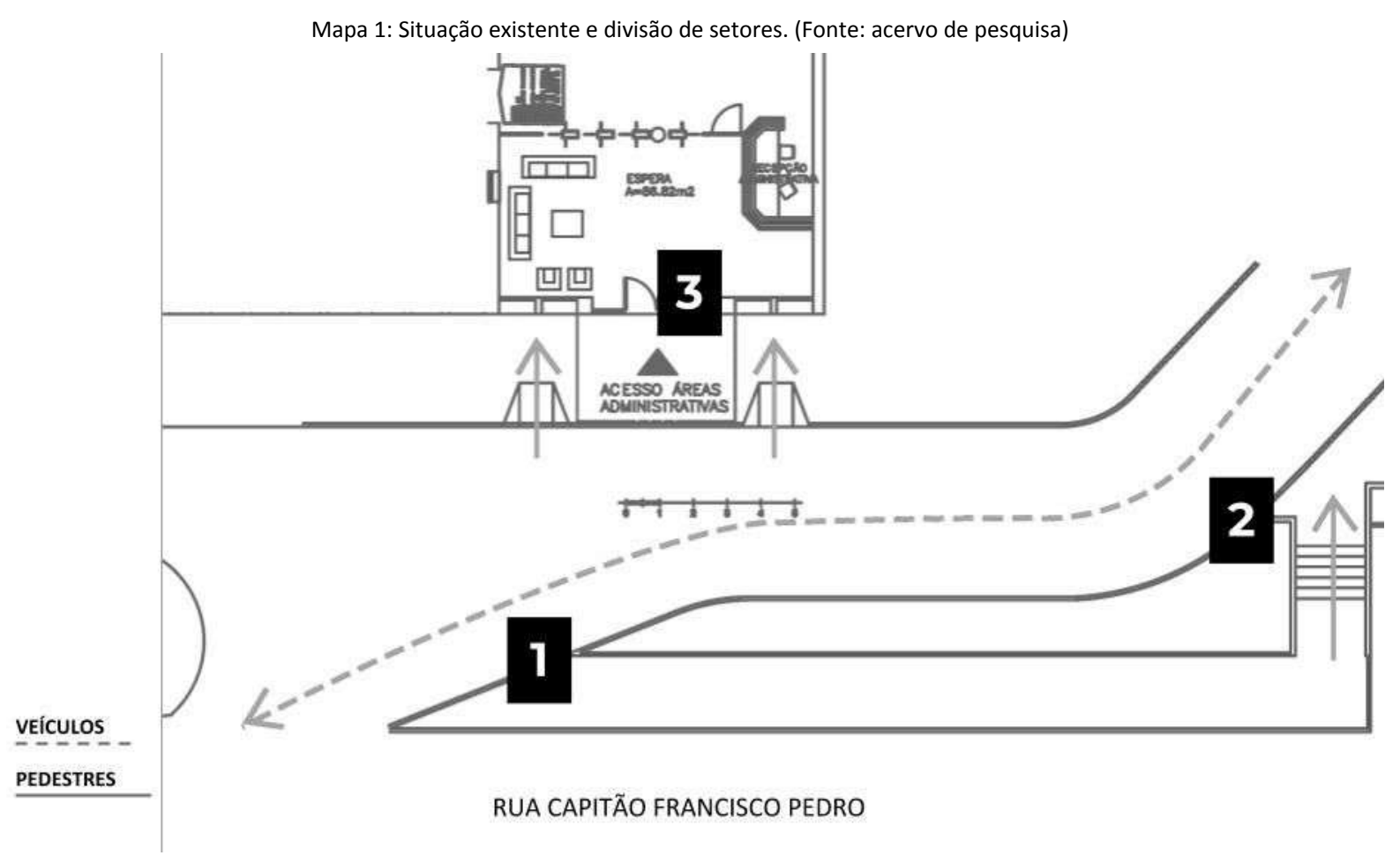

Para o início da compreensão do espaço, o mapa foi dividido em 3 trechos e cada um possui uma finalidade de análise diferente, o trecho 1 diz respeito ao passeio de pedestres em meio ao de veículos, o trecho 2 , ao desnível e o trecho 3 , à entrada da recepção do bloco. Com isso, percebeu-se a necessidade de adoção de outro metodo de divisao, sendo este por problemáticas (caminhos obstáculos, rampas), para que a leitura do espaço ficasse mais homogênea e objetiva.

\section{Análise subjetiva presencial por vivência no local}




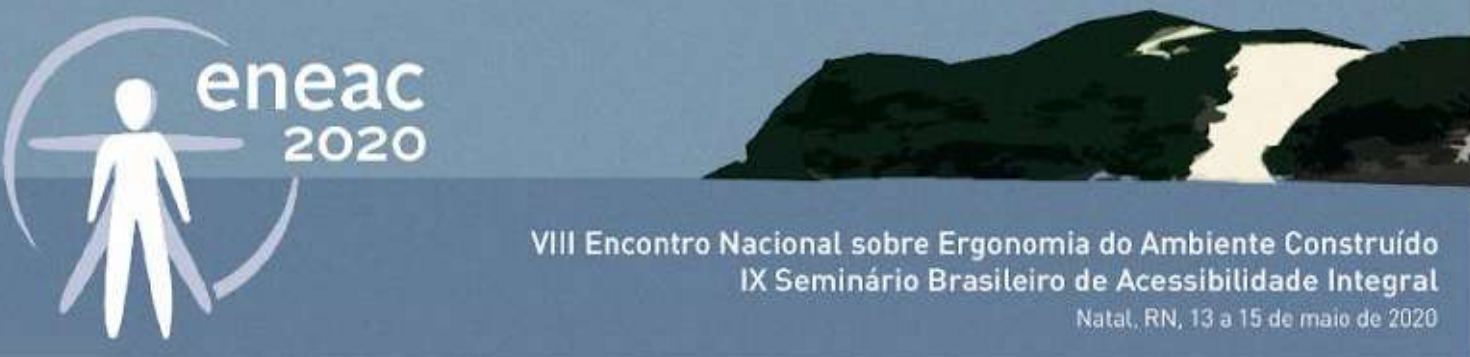

A primeira etapa da análise consistiu em uma visita ao hospital, aspirando captar as dificuldades obtidas pelos seus usuários. Nenhum dos visitantes possuía nenhum tipo de problema de locomoção. A ida se deu no período da tarde, priorizando as áreas externas e de recepção. Lá se pode notar como era cansativa a caminhada, e como o acesso de um bloco a outro era difícil.

\section{Levantamento}

Com uma maior noção dos problemas enfrentados pelos usuários do espaço, foram levantados os caminhos que se pensou poder ter alguma inconveniência, como também dimensões e inclinações de rampas e os obstáculos que poderiam causar eventuais acidentes, tendo sido todos listados:

\section{Caminhos}

O passeio em frente ao hospital possui piso altamente trepidante, e também possui problemas de assentamento, fatos que fazem com que seja mais confortável pro usuário andar pela via de veículos do que pela calçada.

A faixa de pedestres da Rua Capitão Francisco Pedro se encontra em posição adequada, no meio da via, tendo em vista que não há semaforização nas esquinas, fazendo com o que o carro precise ir até o final para checar se pode atravessar, impossibilitando uma faixa de pedestres nas esquinas, entretanto, a faixa existente se encontra muito apagada, e sem sinalização apropriada.

No tocante ao acesso da praça do hospital à calçada da recepção, não existe uma faixa de pedestres na via interna, diminuindo a segurança dos pedestres na travessia dessa via.

\section{Obstáculos}

Na faixa livre são postas bancas de jornal e bancos de plástico, impossibilitando a passagem dos pedestres em geral.

Outro obstáculo existe devido ao fato de que a calçada se encontra em nível diferente da edificação, com, aproximadamente $80 \mathrm{~cm}$ de diferença e o acesso do nível do passeio ao nível da entrada do hospital se dá unicamente por uma escada.

\section{Rampas}

A única rampa de acesso é a de veículos, com $7 \mathrm{~m}$ de largura e $30 \%$ de inclinação.

\section{Identificação de incompatibilidades com normas e manuais que regularizam os pontos levantados}

Em comparação com a NBR 9050, com a NBR 15438 e com o Manual de Sinalização de Trânsito, foram levantados pontos críticos a serem mostrados a seguir, mantendo a ordem do tópico anterior.

\section{Caminhos:}

"Os pisos devem ter superfície regular, firme, estável e antiderrapante sob qualquer condição, que não provoque trepidação em dispositivos com rodas (cadeiras de rodas ou carrinhos de bebê)." 


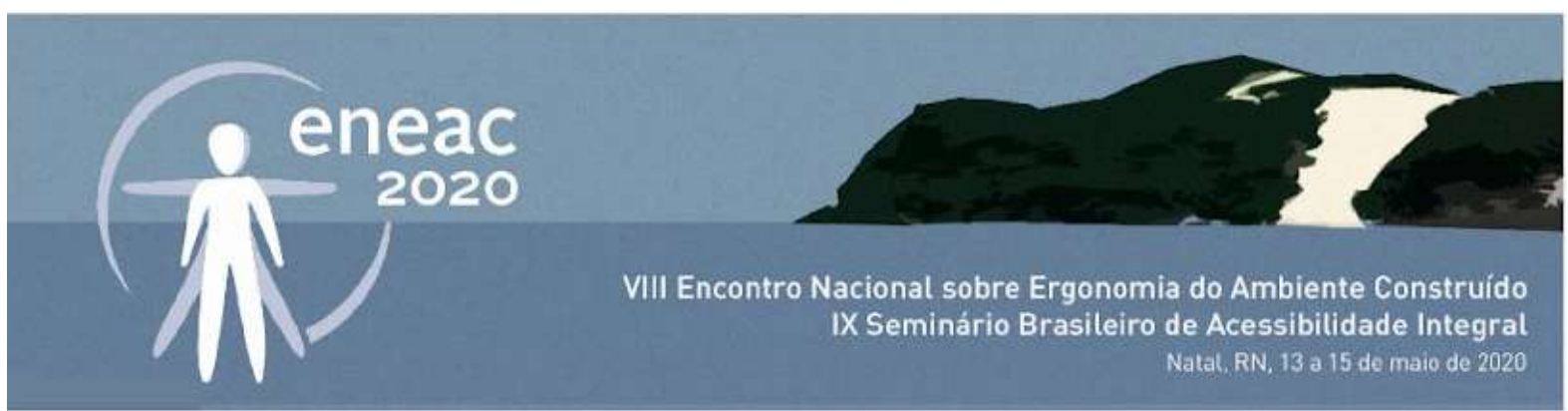

Como foi aferido no levantamento, há piso trepidante sem assentamento adequado no passeio (FIGURA 1).

A faixa de pedestres da rua Capitão Francisco Pedro, em frente ao hospital, que se encontra apagada, configura como inválida, pois, de acordo com a NBR 15438 - Especificações Técnicas - Sinalização Viária, no tópico 1.1.2 (TINTAS PARA SINALIZAÇÃO), um dos requisitos qualitativos é a "integridade inalterada" da faixa, anulando presença da faixa existente, e:

\section{"A FTP (Faixa de Travessia de Pedestres) deve ser utilizada em locais onde haja necessidade de ordenar e regulamentar a travessia de pedestres."}

\section{- Manual Brasileiro de Sinalização de Trânsito}

Sendo, assim, necessária a manutenção da faixa, tendo em vista o grande fluxo de pedestres causado por todo o complexo hospitalar e universitário da área.

Ainda baseado na norma citada pelo Manual Brasileiro de Sinalização de Trânsito, a falta de faixa de travessia de pedestres na via interna, ligando a praça existente à calçada da recepção o hospital é um ponto problemático, tanto pela falta de segurança aos pedestres que fazem, quanto pelo fato de o cadeirante ter que descer um meio fio para atravessar a rua, atravessando fora da faixa, para chegar na calçada da recepção.

Tabela 1: Incompatibilidades ilustradas (fotos 1, 2, 3, 4, 5, 6, 7 e 8 dos acessos vinculados ao HUWC)

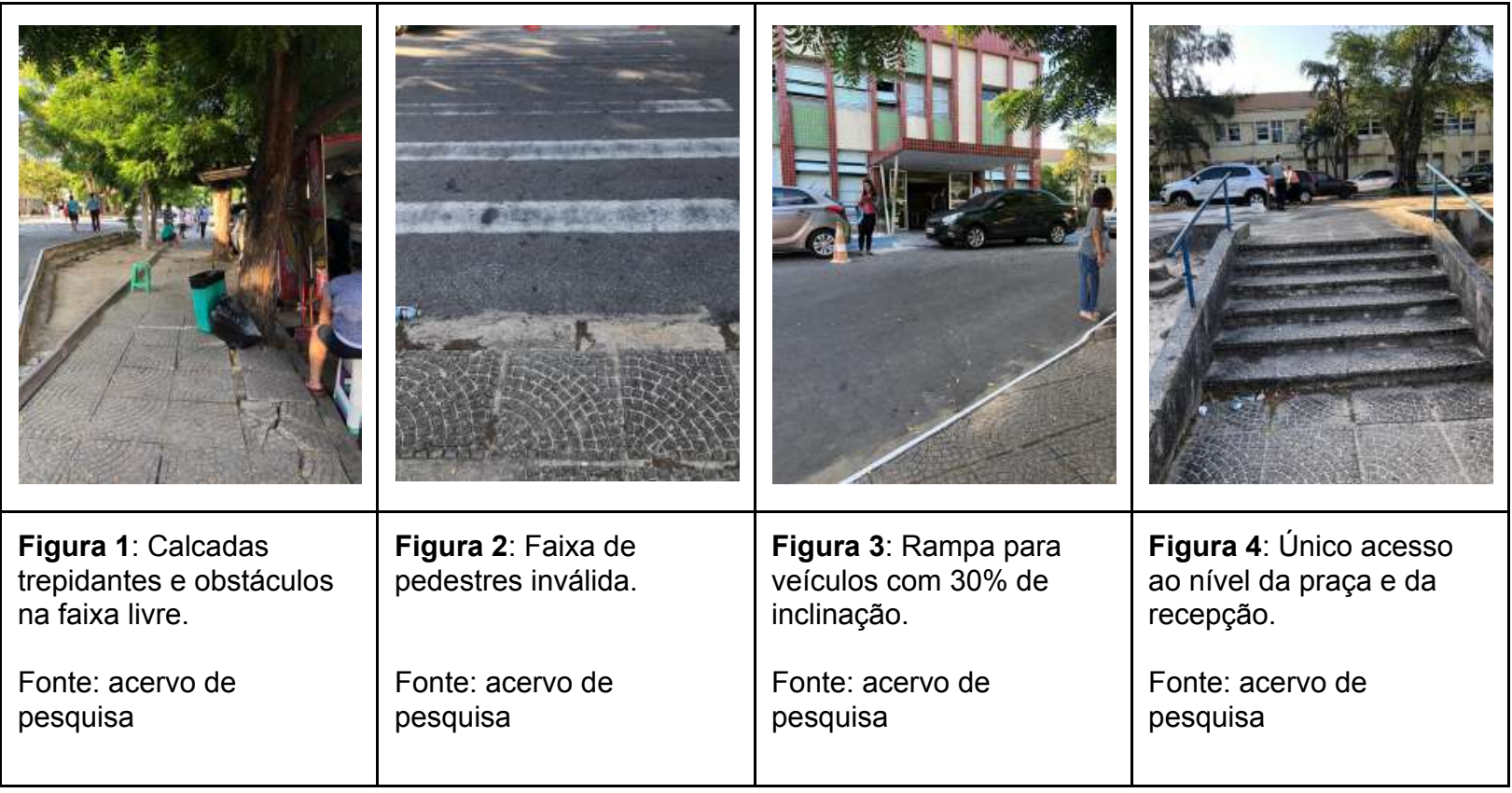




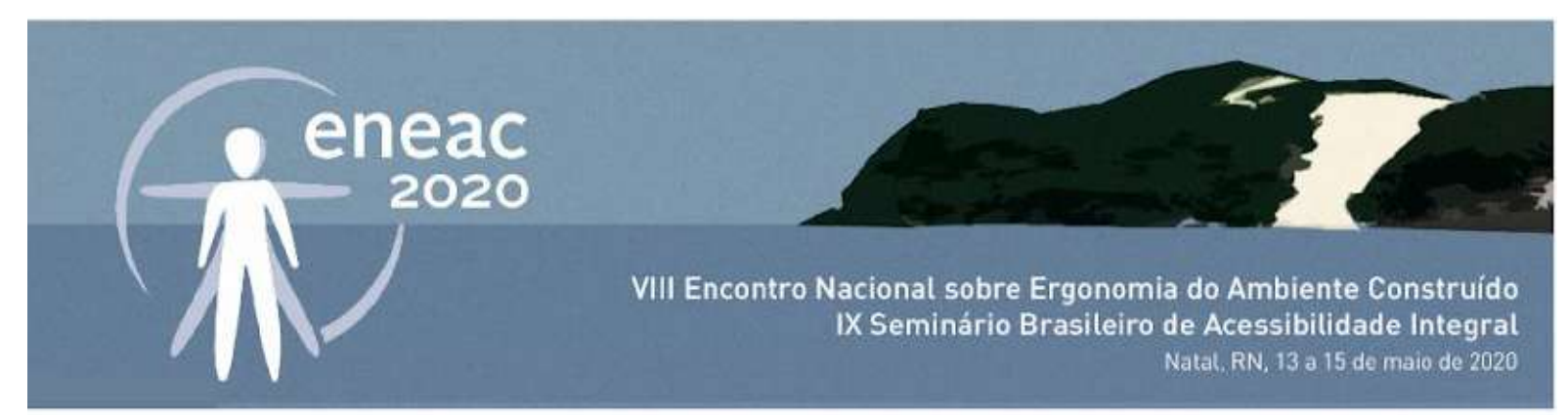

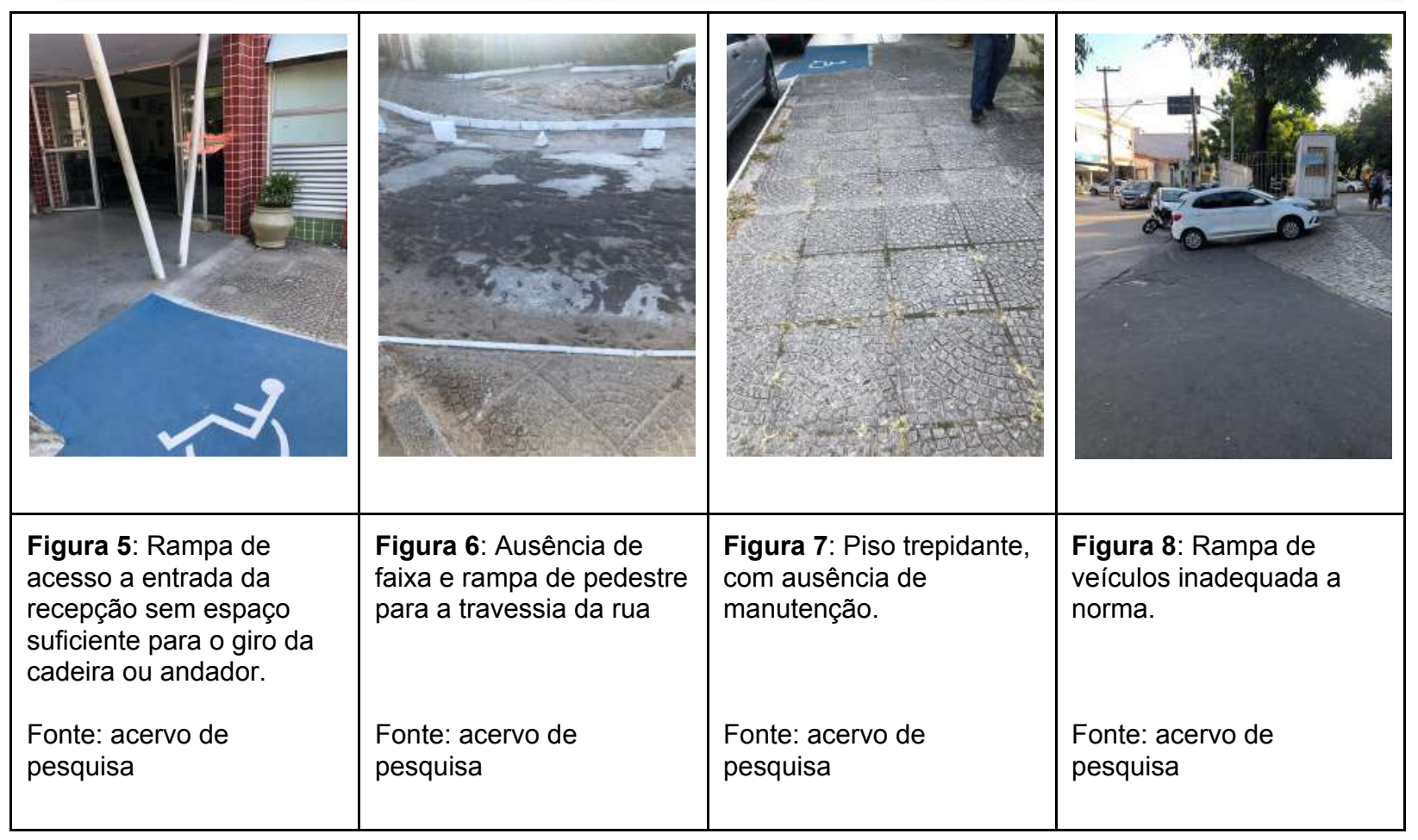

\section{Obstáculos}

Na FIGURA 1, pode-se observar a interferência da banca de jornal, de uma lixeira, de bancos, e dos ramos de uma árvore, deixando a faixa livre menor em largura e em altura que exigido em norma:

"Calçadas, passeios e vias exclusivas de pedestres devem incorporar faixa livre com largura mínima recomendável de 1,50m, sendo o mínimo admissivel de 1,20m e altura livre mínima de 2,10m".

\section{- $\quad$ NBR 9050}

No tocante à escada, não se faz observações à escada em si, mas sim ao fato de ela ser a única forma de passagem entre os desníveis, deixando a edificação inacessível à cadeirantes, como exige a norma:

"Nas edificações e equipamentos urbanos todas as entradas devem ser acessiveis, bem como as rotas de interligação às principais funções do edifício." 


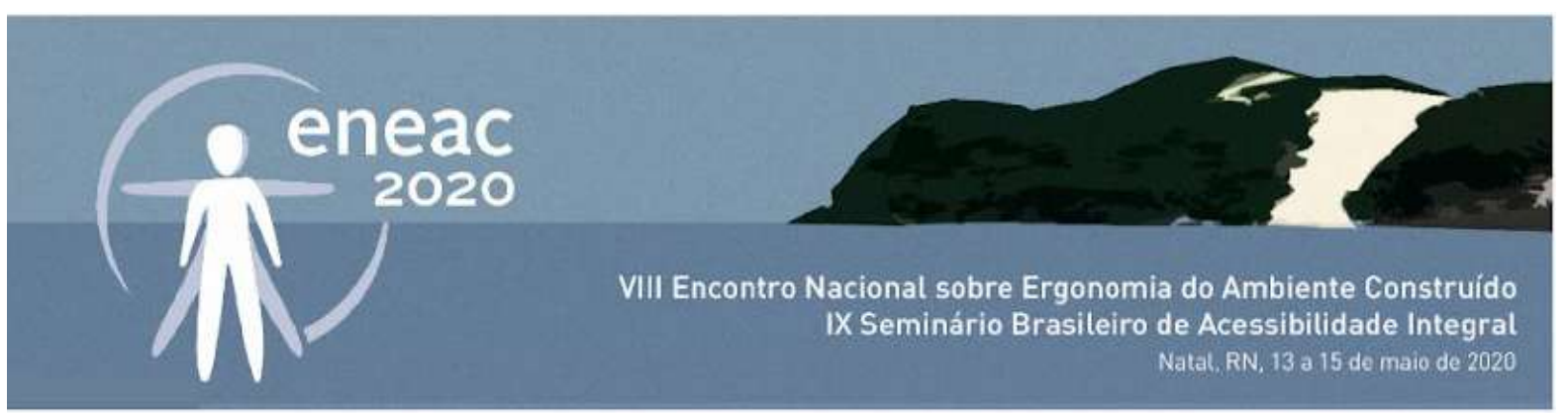

Tabela 2: Dimensionamento de rampas (Tabela 5 da NBR 9050)

\begin{tabular}{|c|c|c|}
\hline $\begin{array}{c}\text { Inclinação admissível em cada } \\
\text { segmento de rampa } \\
\text { i (\%) }\end{array}$ & $\begin{array}{c}\text { Desníveis máximos de cada } \\
\text { segmento de rampa } \\
\mathrm{h}(\mathrm{m})\end{array}$ & $\begin{array}{c}\text { Número máximo de } \\
\text { segmentos de rampa }\end{array}$ \\
\hline $5,00(1: 20)$ & 1,50 & Sem limite \\
\hline $5,00(1: 20)<\mathrm{i} \leq 6,25(1: 16)$ & 1,00 & Sem limite \\
\hline $6,25(1: 16)<\mathrm{i} \leq 8,33(1: 12)$ & 0,80 & 15 \\
\hline
\end{tabular}

Tendo em vista a inexistência de rampas específicas para pedestres, notou-se que cadeirantes fazem o acesso à edificação pela rampa de veículos, entretanto, essa rampa não se encontra adequada para tal, tendo em vista sua inclinação de $30 \%$ (FIGURA 3).

\section{DISCUSSÃO DE RESULTADOS}

\section{Viabilidade do projeto}

Visando as incompatibilidades, faz-se urgente a reforma dos acessos do hospital. As considerações feitas mostram a inviabilidade de uso dos usuários em geral, principalmente de pessoas com deficiência física, ao hospital, que é um equipamento público, onde, teoricamente deveria poder ser acessado por todos.

O direito de ir e vir, princípio básico da Constituição Federal de 1988, está sendo violado pela negligência com questões básicas de acesso, urge então um projeto de reforma que vise atender todos os públicos que frequentam o local.

A maioria das alterações não mexem com estrutura. A alteração mais significativa é a de implantação de uma rampa com inclinação adequada, ligando o nível da calçada ao nível da edificação.

\section{Relatório com possibilidades de compatibilização}

\section{Caminhos}

- Substituição do piso existente no passeio por um piso antiderrapante e não trepidante, fazendo a manutenção no tempo indicado pelo fornecedor.

- Manutenção da faixa de travessia de pedestres existente

- Criação de faixa entre a praça e a calçada do hospital, na via interna da edificação, com rampas acessíveis da calçada à faixa, vencendo o meio-fio.

\section{Obstáculos}

- Realocação da banca de revista para a praça próxima. 


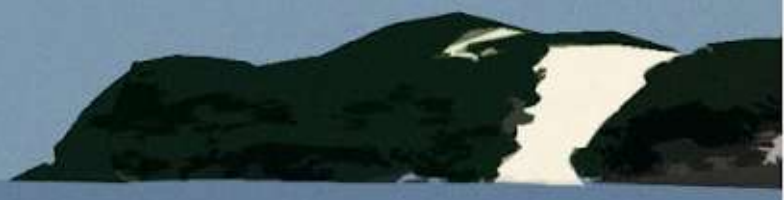

VIII Encontro Nacional sobre Ergonomia do Ambiente Construído IX Seminário Brasileiro de Acessibilidade Integral

Natal, RN, 13 a 15 de maio de 2020

\section{Rampas}

- Criação de uma rampa com inclinação de $8,33 \%$ no passeio, vencendo a o desnível entre os passeios da via e da calçada do hospital, sendo o mais próximo possível da entrada da recepção.

\section{PROJETO DE COMPATIBILIZAÇÃO}

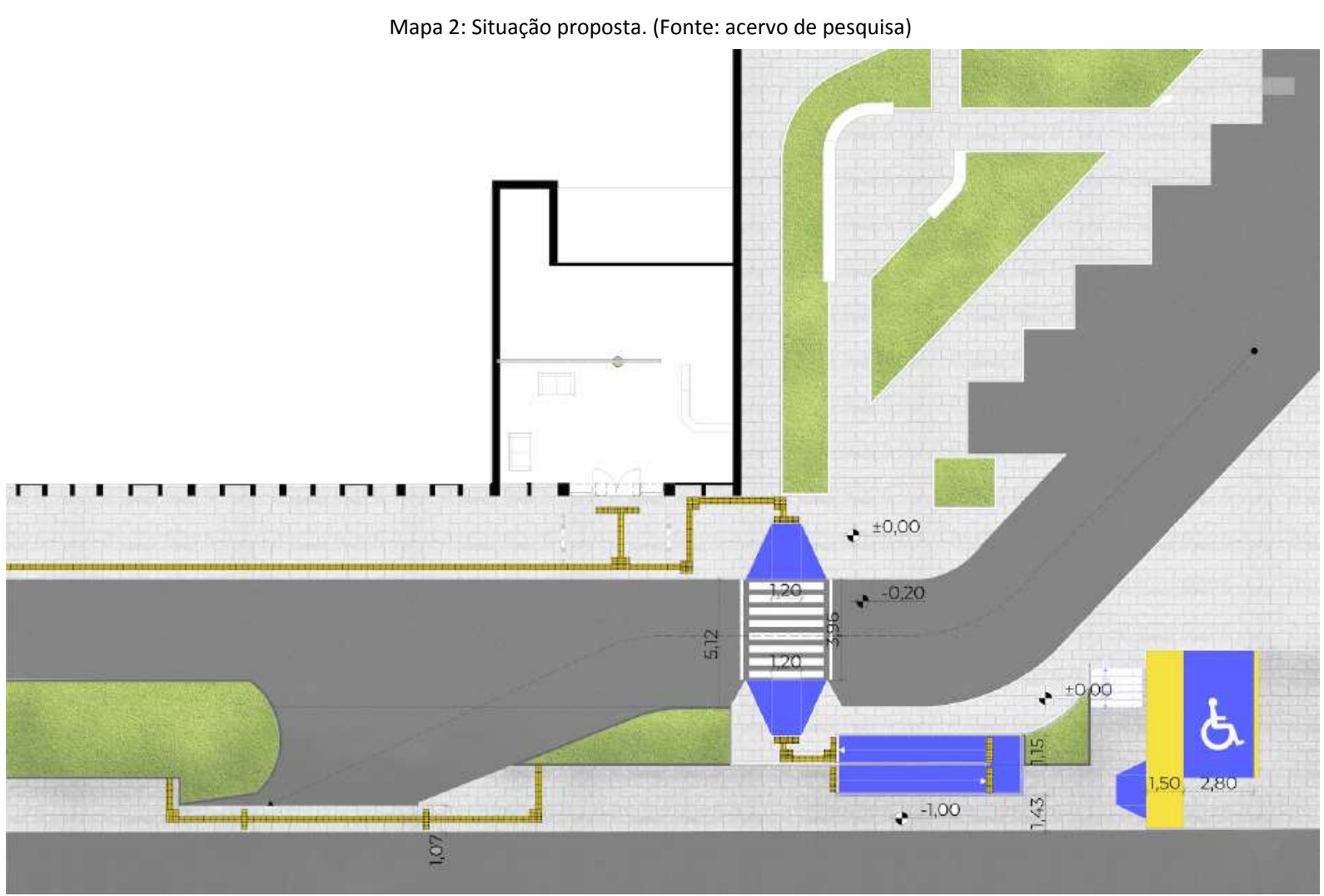

Visando suprir as necessidades anteriormente listadas, o projeto de adequabilidade conta com um projeto de paginação de piso tátil, um acesso de rampas adequadas a norma, o assentamento de uma calçada, onde antes era área permeável, formando, assim, caminhos lógicos ao longo do percurso, além de propor uma vaga de estacionamentos para cadeirantes.

Outro problema citado foi a locação de uma banca de jornal, sendo esta realocada para a praça, não muito longe de onde costumava ficar, para que não haja nenhum prejuízo ao proprietário ou aos clientes.

Como o espaço das calçadas era limitado e havia a necessidade de um guia para cegos, foi pensado um guarda-corpo (IMAGEM 1) que pudesse servir para a função. Tendo sua base de alvenaria, a bengala bater e seguir o percurso sem maiores dificuldades e a parte superior do guarda-corpo de cilindro metálicos se justifica no sentido de barrar o mínimo possível da visão. 


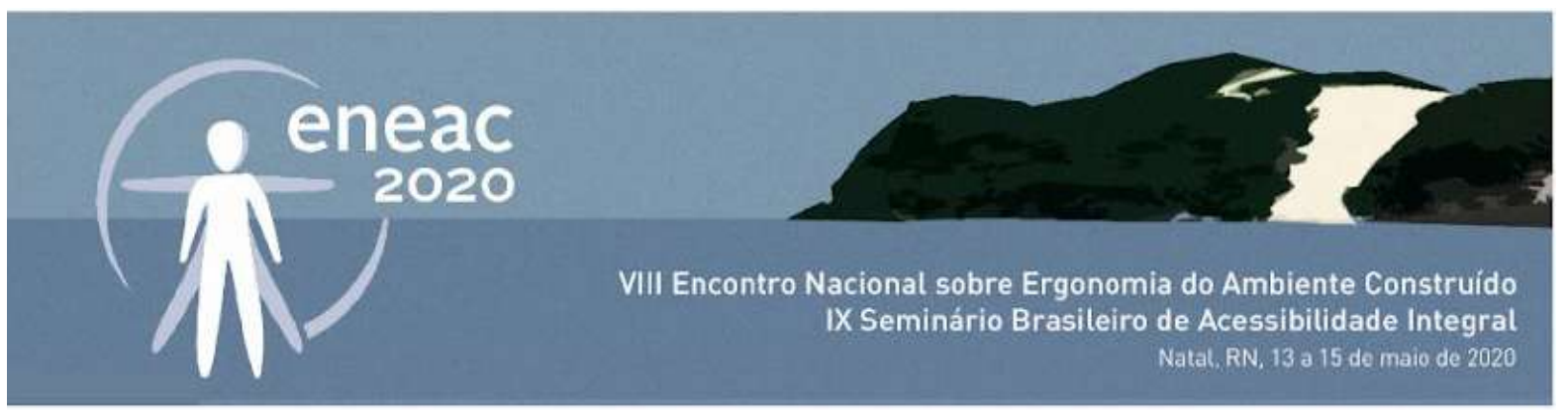

Figura 9: Detalhe do guarda-corpo. (Fonte: acervo de pesquisa).

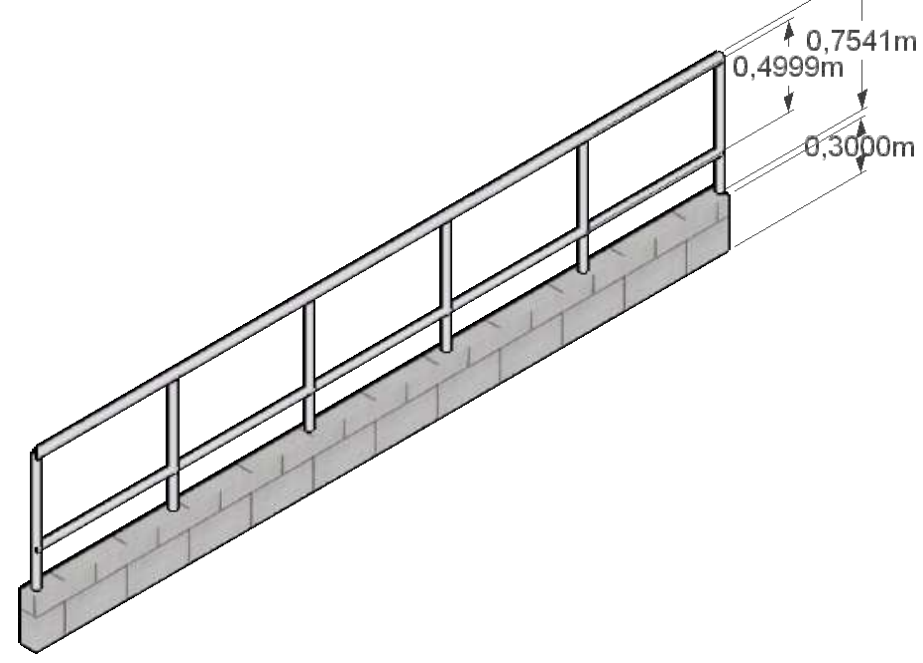

Figura 10: Perspectiva do projeto. (Fonte: acervo de pesquisa).

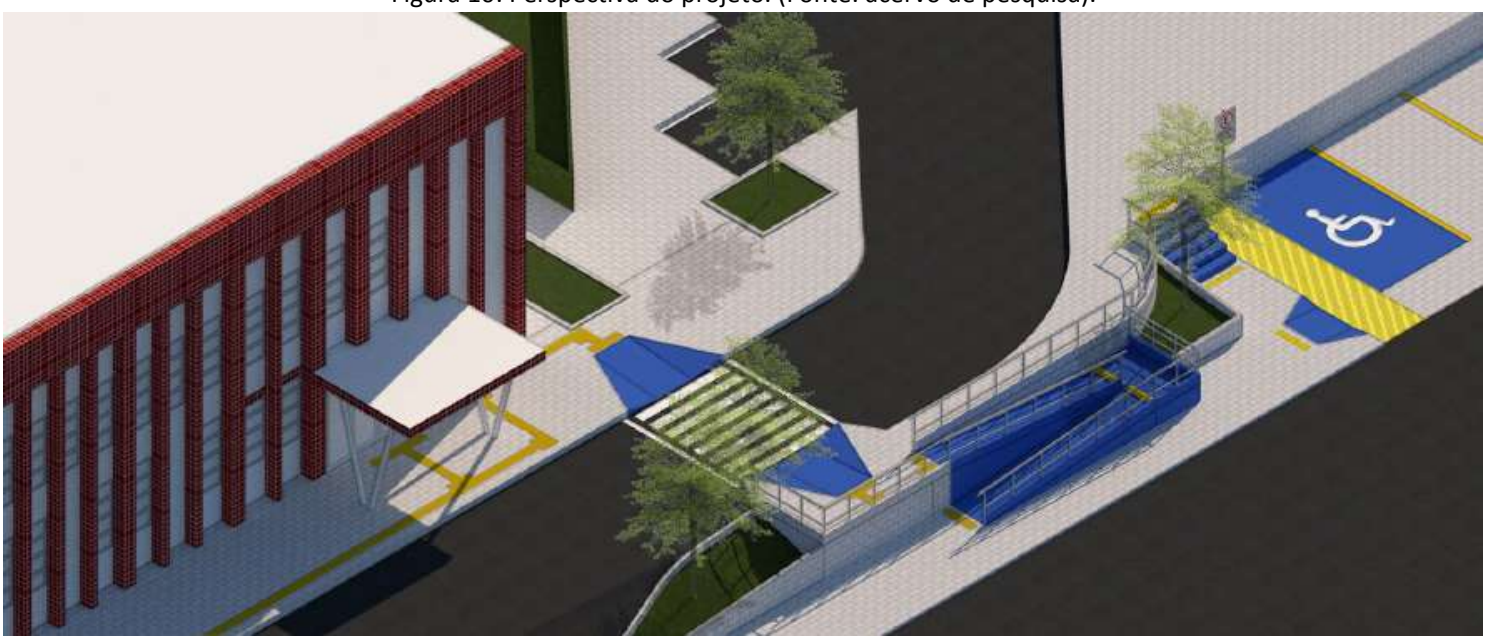

Figura 11: Perspectiva do projeto. (Fonte: acervo de pesquisa). Figura 12: Perspectiva do projeto. (Fonte: acervo de pesquisa).
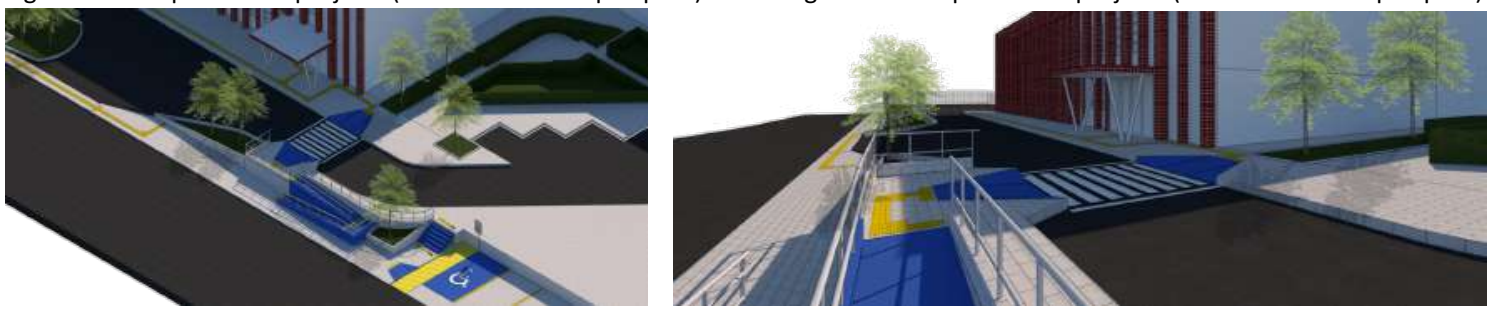

\section{CONSIDERAÇÕES FINAIS}

Adequar um ambiente a norma de acessibilidade, vai além de cumprir a lei, é deixar um ambiente inclusivo e acessível a todas as pessoas que o frequentam, além de entender que é de competência da cidade oferecer a todos seus habitantes espaços humanitários e planejados, percebendo a importância do convívio e do lazer e valorizá-los de modo a incentivá-los tal qual qualquer outro serviço. No que diz respeito ao caso estudado, onde se localizam praças e bancas, que podem ser 
entendidos como espaços citados, a mobilidade e a acessibilidade devem ser priorizadas de modo que atenda a necessidade do local.

Após a análise concluiu-se que a chegada a recepção não atende a todos os tipos de público que poderia frequentar, principalmente por se tratar de um hospital, onde pessoas podem ter dificuldade de locomoção provocada até por alguma eventual doença.

Então foi percebido a necessidade da criação de rampas para pedestre, além de acesso a escada mais próximo a recepção, ambas atendendo a NBR 9050, como também a criação de faixa para pedestre para o acesso seguro do passeio à recepção.

\section{AGRADECIMENTOS}

Agradecemos ao corpo docente da universidade por todo o conhecimento atribuído, em especial à professora Zilsa Santiago, pela disciplina ministrada que possibilitou e incentivou esse artigo e esse tema que faz parte da atualidade da nossa cidade natal. Agradecemos também ao HUWC, que abriu as portas para as avaliações feitas e auxiliou em tudo o que foi necessário.

\section{REFERÊNCIAS BIBLIOGRÁFICAS}

BLOG PROJEMAK, 2016. O que é a Norma NBR 9050. Disponível em:

<http://projemak.com.br/o-que-e-a-norma-nbr-9050/>. Acesso em: 27 de novembro de 2019.

ASSOCIAÇÃO BRASILEIRA DE NORMAS TÉCNICAS. NBR 9050: Acessibilidade a edificações, mobiliário, espaços e equipamentos urbanos. Rio de Janeiro, p. 162. 2015

ASSOCIAÇÃO BRASILEIRA DE NORMAS TÉCNICAS. NBR 15438:Sinalização horizontal viária - Tintas - Métodos de ensaio. 2013.

CONSELHO NACIONAL DE TRÂNSITO. Manual Brasileiro de Sinalização de Trânsito. 2007.

SANTIAGO, Zilsa Maria Pinto, DO NASCIMENTO, Raquel Martins, SALES, Fernanda Rocha. Acessibilidade em edifícios públicos: estudo de caso - instituto de educação física e esportes no Campus do Pici - UFC. VI Encontro Nacional de Ergonomia do Ambiente Construído (ENEAC), Recife, 2014.

CEARÁ. Guia de Acessibilidade: Espaços públicos e edificações. Elaboração: Nadja G.S.Dutra Montenegro; Zilsa Maria Pinto Santiago; Valdemice Costa de Sousa. Fortaleza: SEINFRA-CE, 2009.

GEHL, Jan. Cidade Para Pessoas. Tradução: Anita Di Marco. São Paulo: Perspectiva, 2013.

SANTIAGO, Zilsa. MORANO, Raquel. ACESSIBILIDADE COMO FATOR DE INCLUSÃO NA GESTÃO DAS CIDADES E DE POLÍTICAS PÚBLICAS: avaliação e vivência de grupo de pessoas com deficiência na Avenida Beira Mar em Fortaleza. 2019.

SANTIAGO, Zilsa. MORANO, Raquel. Distribuição espacial e desigualdade na cidade - onde estão as pessoas com deficiência visual em Fortaleza?

SANTIAGO, Zilsa. LIMA, Manuela. VILLAROUCO, Vilma. POLÍTICAS PÚBLICAS PARA IDOSOS: cidades para a 3a idade. 2019

ROCHA, Carlos Bruno Oliveira. SANTIAGO, Zilsa Maria Pinto. RIBEIRO, Fernanda Lessa. ESPAÇO PÚBLICO E ESPAÇO EDIFICADO: uma análise dos equipamentos sociais agregados às praças de Fortaleza sob o enfoque da acessibilidade universal. 